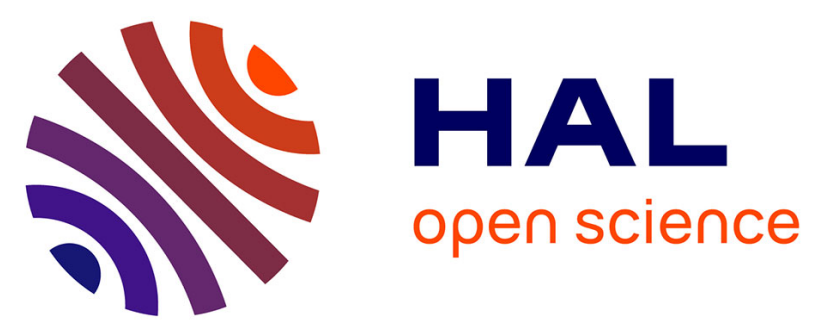

\title{
Synergistic influence of topomimetic and chondroitin sulfate-based treatments on osteogenic potential of Ti-6Al-4V
}

Béatrice Labat, Sandrine Morin-Grognet, Fabien Gaudière, Lucia Bertolini-Forno, Olivier Thoumire, Jean-Pierre Vannier, Guy Ladam, Hassan

Atmani

\section{To cite this version:}

Béatrice Labat, Sandrine Morin-Grognet, Fabien Gaudière, Lucia Bertolini-Forno, Olivier Thoumire, et al.. Synergistic influence of topomimetic and chondroitin sulfate-based treatments on osteogenic potential of Ti-6Al-4V. Journal of Biomedical Materials Research Part A, 2016, 104 (8), pp.1988-2000. 10.1002/jbm.a.35732 . hal-02337247

\section{HAL Id: hal-02337247 \\ https://hal.science/hal-02337247}

Submitted on 29 Oct 2019

HAL is a multi-disciplinary open access archive for the deposit and dissemination of scientific research documents, whether they are published or not. The documents may come from teaching and research institutions in France or abroad, or from public or private research centers.
L'archive ouverte pluridisciplinaire HAL, est destinée au dépôt et à la diffusion de documents scientifiques de niveau recherche, publiés ou non, émanant des établissements d'enseignement et de recherche français ou étrangers, des laboratoires publics ou privés. 


\title{
Synergistic influence of topomimetic and chondroitin sulfate-based treatments on osteogenic potential of Ti-6Al-4V
}

\author{
B Eatrice Labat, Sandrine Morin-Grognet, Fabien Gaudiè, Lucia \\ Bertolini-Forno, Olivier Thoumire, Jean-Pierre Vannier, Guy Ladam, Hassan \\ Atmani, Béatrice Labat, Fabien Gaudière
}

\section{To cite this version:}

B Eatrice Labat, Sandrine Morin-Grognet, Fabien Gaudiè, Lucia Bertolini-Forno, Olivier Thoumire, et al.. Synergistic influence of topomimetic and chondroitin sulfate-based treatments on osteogenic potential of Ti-6Al-4V. Journal of Biomedical Materials Research Part A, Wiley, 2016, 104 (8), pp.19882000. 10.1002/jbm.a.35732 . hal-02337247

\section{HAL Id: hal-02337247 \\ https://hal.archives-ouvertes.fr/hal-02337247}

Submitted on 29 Oct 2019

HAL is a multi-disciplinary open access archive for the deposit and dissemination of scientific research documents, whether they are published or not. The documents may come from teaching and research institutions in France or abroad, or from public or private research centers.
L'archive ouverte pluridisciplinaire HAL, est destinée au dépôt et à la diffusion de documents scientifiques de niveau recherche, publiés ou non, émanant des établissements d'enseignement et de recherche français ou étrangers, des laboratoires publics ou privés. 


\title{
Synergistic influence of topomimetic and chondroitin sulfate-based treatments on osteogenic potential of Ti-6AI-4V
}

\author{
Béatrice Labat, ${ }^{1,2}$ Sandrine Morin-Grognet, ${ }^{1,2}$ Fabien Gaudière, ${ }^{1,2}$ Lucia Bertolini-Forno, ${ }^{1,2}$ \\ Olivier Thoumire, ${ }^{1,2}$ Jean-Pierre Vannier, ${ }^{1,2,3}$ Guy Ladam, ${ }^{1,2}$ Hassan Atmani ${ }^{1,2}$ \\ ${ }^{1}$ Normandie Université, Caen, France \\ ${ }^{2}$ Laboratoire De Biophysique Et Biomatériaux (La2B - MERCI EA 3829), Université De Rouen, Centre Universitaire D’Évreux, 1 \\ Rue Du 7ème Chasseurs, Évreux Cedex, 27002, France \\ ${ }^{3} \mathrm{MERCl}$, EA 3829, Faculté De Médecine-Pharmacie, Université De Rouen, 22 Boulevard Gambetta, Rouen, 76183, France
}

Received 16 October 2015; revised 10 March 2016; accepted 29 March 2016

Published online 00 Month 2016 in Wiley Online Library (wileyonlinelibrary.com). DOI: 10.1002/jbm.a.35732

\begin{abstract}
We combined topographical and chemical surface modifications of Ti-6Al-4V (TA6V) to improve its osteogenic potential. By acid-etching, we first generated topomimetic surface features resembling, in size and roughness, bone cavities left by osteoclasts. Next, we coated these surfaces with biomimetic Layer-by-Layer films (LbL), composed of chondroitin sulfate $A$ and poly-L-lysine that were mechanically tuned after a post-treatment with genipin. The structural impact of each surface processing step was thoroughly inspected. The desired nano/microrough topographies of TA6V were maintained upon LbL deposition. Whereas no significant promotion of adhesion and proliferation of MC3T3-E1
\end{abstract}

preosteoblasts were detected after independent or combined modifications of the topography and the chemical composition of the substrates, osteogenic maturation was promoted when both surface treatments were combined, as was evidenced by significant long-term matrix mineralization. The results open promising route toward improved osseointegration of titanium-based implants. () 2016 Wiley Periodicals, Inc. J Biomed Mater Res Part A: 00B:000-000, 2016.

Key Words: titanium alloy, topography, chondroitin sulfate, genipin, pre-osteoblasts

How to cite this article: Labat B, Morin-Grognet $S$, Gaudière F, Bertolini-Forno L, Thoumire O, Vannier J-P, Ladam G, Atmani $\mathrm{H}$. 2016. Synergistic influence of topomimetic and chondroitin sulfate-based treatments on osteogenic potential of Ti-6Al-4V. J Biomed Mater Res Part A 2016:00A:000-000.

\section{INTRODUCTION}

Titanium alloys, in particular Ti-6Al-4V (TA6V), are biomaterials of choice in dentistry and orthopaedic surgery for their appropriate mechanical properties but, they are classified as bioinert materials because of their low capability to promote intimate contact with host bone tissue, required for optimal implant osseointegration. Therefore, strategies have been explored to render them bioactive through topographical or chemical surface modifications mimicking the bone tissue microenvironment.

To texture the surfaces with a well-defined nano-, submicro-, or micrometric roughness, i.e. in the relevant range capable to influence the response of bone cells, blasting, oxidation, and acid etching (AE) are commonly used techniques. ${ }^{1-4}$ Nanoscale topographies, for instance, were reported to improve bone-cell/biomaterial interactions., Elsewhere, smoothest surfaces were reported to promote osteoblast anchoring and proliferation, while roughest ones favored differentiated cell morphologies and matrix mineralization.,8 However, the existence of a unique range of roughness promoting osteogenesis is controversial as far as bone cells are rather sensitive to combinations of nano- and microtextures. ${ }^{9,10} \mathrm{AE}$ of Ti-based materials allows to generate surfaces with such multiscale topographies, depending on acid concentration, temperature, and duration of the treatment. ${ }^{11}$

To further mimic the bone micro-environment, the textured surfaces can be covered with thin polymer coatings matching the composition and mechanical properties of the bone extracellular matrix (ECM). To this end, various proteins or peptides (collagen, fibronectin, RGD derivatives...) allowing integrin-mediated cell attachment can be recruited. ${ }^{12,13}$ Natural polysaccharides such as glycosaminoglycans (GAGs) are also relevant candidates, as they naturally combine to proteins into proteoglycans (PGs), and readily bind various endogenous biomolecules such as growth factors in the ECM. ${ }^{14}$ It has been shown that PG coating of Ti-based materials was a prerequisite for bone cells attachment, ${ }^{15}$ and that decorin and biglycan (noncollagenous PGs) were involved in the accumulation of calcium at mineralization sites. ${ }^{16}$ Chondroitin sulfate (CS), a ubiquitous sulphated GAG composing most of the connective tissues such as cartilage and bone, is of particular interest as it regulates osteogenesis. ${ }^{17,18}$ 
TABLE I. Nomenclature and Description of the Substrates Prepared

\begin{tabular}{|c|c|}
\hline Nomenclature & Description \\
\hline TA6V & Nontreated Ti-6AI-4V \\
\hline TA6V-PLL & Nontreated Ti-6AI-4V + PEI/(CSA/PLL) 6 \\
\hline TA6V-CSA & Nontreated Ti-6AI-4V + PEI/(CSA/PLL) $/$ CSA \\
\hline TA6V-PLL-GnP & Nontreated Ti-6AI-4V + PEI/(CSA/PLL) $6+\mathrm{GnP}$ \\
\hline TA6V-CSA-GnP & Nontreated Ti-6Al-4V + PEI/(CSA/PLL) $6 / C S A+G n P$ \\
\hline $\mathrm{TA} 6 \mathrm{~V}-A E$ & Acid-etched Ti-6Al-4V \\
\hline TA6V-AE-PLL & Acid-etched Ti-6AI-4V + PEI/(CSA/PLL) 6 \\
\hline TA6V-AE-CSA & Acid-etched Ti-6AI-4V + PEI/(CSA/PLL) $6 /$ CSA \\
\hline TA6V-AE-PLL-Gnp & Acid-etched Ti-6Al-4V + PEI/(CSA/PLL) 6 + GnP \\
\hline TA6V-AE-CSA-GnP & Acid-etched Ti-6AI-4V + PEI/(CSA/PLL) $6 / \mathrm{CSA}+\mathrm{GnP}$ \\
\hline
\end{tabular}

Layer-by-Layer (LbL) films (or polyelectrolyte multilayers) are widely studied, versatile polymer coatings allowing to modify surfaces of any chemical nature and geometry. ${ }^{19}$ The buildup of LbL films consists in successive depositions of oppositely charged polyelectrolytes mainly through electrostatic interactions. This produces nano-to micrometric coatings with different potential functionalities. Many biofunctional, biological, and biomimetic compounds, such as proteins and polysaccharides, can be used as components of LbL films, for instance atop Ti-based biomaterials. $^{20,21}$ In particular, the use of such coatings as reservoirs for local controlled release of bioactive compounds (growth factors, hormones) and/or therapeutics drugs (antibiotics, antifungals, anticancerous, and anti-inflammatory molecules) in diseased tissues, is a growing field of interest. ${ }^{22}$ Some works have reported on LbL films composed of the anionic GAG chondroitin sulfate A (CSA) associated with cationic poly-L-lysine (PLL) ${ }^{23-26}$ However, GAG-based LbL films are generally too soft because of their hydration such that they mismatch the physiological stiffness of cell microenvironment. Cross-linking methods were developed in order to optimize their mechanical properties, but current crosslinkers such as glutaraldehyde or EDC/NHS are potentially cytotoxic if they remain in their free form, ${ }^{27,28}$ therefore there is a need for biocompatible alternatives. Recently, genipin (GnP), a biological compound extracted from Gardenia fruit, was reported to cross-link LbL films ${ }^{29-31}$ and its biocompatibility was demonstrated in numerous works. Of note, rare papers related apoptotic or antiproliferative effects of genipin treatments, but with cancer cell lines. ${ }^{32,33}$ Henceforward, based on the upmost promising literature, we implemented this natural cross-linking agent in our strategy. We reported in a previous work, that it significantly improved the mechanical properties of our CSA/PLL LbL films and favored adhesion, proliferation, and differentiation of pre-osteoblasts cells. ${ }^{31}$

Here, inspired by the challenge of bone surface mimicry, we combined (i) topographical modification of TA6V substrates exhibiting nano- to microscale roughness, with (ii) further deposition of biomimetic CSA/PLL LbL films mimicking the native bone extracellular matrix. We characterized the topography, the composition and the wettability of the modified surfaces, and the bioactivity was assessed in terms of cell morphology, proliferation and early/late differentiation of MC3T3-E1 pre-osteoblasts.

\section{MATERIALS AND METHODS}

Substrates preparation and $\mathrm{AE}$

TA6Vfoils (Goodfellow, original $\mathrm{Ra} \sim 40 \mathrm{~nm}$ ) were cut into $15 \times 15 \mathrm{~mm}^{2}$ pieces. Before use, all samples were cleaned by sonication, and degreased successively in acetone and ethanol, each for $10 \mathrm{~min}$, with intermediate rinsing steps with ultrapure water, and finally dried under a flow of argon. With the aim of nano- and micro-structuring the surfaces, AE of the TA6V substrates was performed into concentrated $\mathrm{H}_{2} \mathrm{SO}_{4}\left(50 \%\right.$ in water) for $1 \mathrm{~h}$ at $60^{\circ} \mathrm{C}$. The corresponding loss of material was controlled by weighing the substrates before and after the AE treatment. In the following, the nontreated and acid-etched substrates will be denoted as TA6V and TA6V-AE, respectively.

\section{Polyelectrolyte solutions, LbL assembly, and genipin cross-linking}

Solutions of CSA (20-30 kDa, Sigma) and PLL (40-60 kDa, Sigma) at $1 \mathrm{mg} \mathrm{mL}^{-1}$, and solutions of poly(ethyleneimine) (PEI, branched, $750 \mathrm{kDa}, 50 \mathrm{wt} \%$ solution in water, Sigma) at $5 \mathrm{mg} \mathrm{mL}^{-1}$, were prepared in saline Tris/ $\mathrm{NaCl}$ buffer $(10 \mathrm{mM}$ Tris, $150 \mathrm{~m} M \mathrm{NaCl}, \mathrm{pH}$ 7.4). Polycationic PEI was always adsorbed as a precursor layer prior to LbL film buildup. To verify that the PEI layer was uniformly adsorbed on the substrates, we labeled PEI molecules with fluorescein isothiocyanate (FITC) fluorescent probe (Sigma) through condensation of the isothiocyanate groups and the primary amines of PEI for $12 \mathrm{~h}$. $\mathrm{PEI}^{\mathrm{FTTC}}$ solution was dialyzed against DI water for $72 \mathrm{~h}$ in order to remove unbound FITC. We then immersed TA6V and TA6V- $A E$ substrates into a PEI ${ }^{\text {FITC }}$ solution $(5 \mathrm{mg}$ $\mathrm{mL}^{-1}$ ) for $30 \mathrm{~min}$, and rinsed them three times prior to observation with a fluorescence microscope (Zeiss Axio Scope A1).

The buildup of $\mathrm{PEI} /(\mathrm{CSA} / \mathrm{PLL})_{6}$ or $\mathrm{PEI} /(\mathrm{CSA} / \mathrm{PLL})_{6} / \mathrm{CSA}$ LbL architectures onto TA6V and TA6V-AE substrates was performed as follows: after the deposition of PEI with the same protocol as for $\mathrm{PEI}^{\mathrm{FITC}}, \mathrm{CSA}$ and PLL were alternatively adsorbed onto the substrates by means of 10-min immersions into the corresponding solutions, followed by three rinses with Tris/NaCl buffer. For the post cross-linking with GnP, we immersed the PEM-coated substrates into solutions of $0.25 \%$ 
$\mathrm{GnP}$ (w/v - Wako Chemicals) in PBS, corresponding to $11 \mathrm{mM}$, for $16 \mathrm{~h}$ at room temperature and rinsed them with PBS. Then, all the substrates were UV-sterilized for $30 \mathrm{~min}$. Table I reports the 10 types of substrates prepared.

\section{In situ LbL assembly assessment by QCM-D}

We followed the buildup of our LbL films on top of Ti-based surfaces by quartz crystal microbalance with dissipation monitoring (QCM-D) using a D300 system (Q-Sense, Sweden) equipped with a QAFC302 flow chamber and QSX310 Ti-coated quartz crystal sensors. QCM-D consists in measuring the resonance frequency shifts $\Delta f$ and the dissipation factor changes $\Delta D$ of the quartz crystal sensor upon material deposition. ${ }^{34} \Delta f$ depends on the total oscillating mass, including coupled water, therefore providing a "wet mass" measurement. The LbL buildup was performed by successive injections of polyelectrolyte solutions ( $5 \mathrm{~mL}$ ) and rinsing solution (5 $\mathrm{mL})$ through the flow chamber, and monitored in situ. $\Delta f$ was measured at the fundamental frequency around $5 \mathrm{MHz}$ and at the 3rd (15 MHz), 5th (25 $\mathrm{MHz}$ ), and 7th (35 MHz) overtones. The fundamental frequency was discarded for it is often affected by contact with the mounting frame. ${ }^{35}$ Analysis of the raw data was carried out using the Q-Tools software provided with the instrument. A Voigt viscoelastic model was used to derive adsorbed masses per unit area and thicknesses assuming a film density of $1.1 \mathrm{~g} \mathrm{~cm}^{-3.36}$

\section{Surface characterization: Topography, roughness, wettability}

Scanning electron microscopy. Before LbL deposition, we inspected the TA6V surfaces before and after AE using a JEOL scanning electron microscope Neoscope JCM 5000 without sample preparation. For LbL-coated TA6V and TA6V- $A E$, we immersed the substrates in a $2.5 \%$ glutaraldehyde solution for $30 \mathrm{~min}$, dehydrated them into two successive acetone baths, and extensively washed them with ultrapure water. Samples were stored at $-80^{\circ} \mathrm{C}$ until used. Prior to Scanning Electron Microscopy (SEM) inspection, the samples were sputter-coated with gold by using a JFC 1300 Autofine coater.

Epifluorescence microscopy. To ascertain the homogeneous coating of TA6V and TA6V-AE substrates with GnP-crosslinked LbL films, we took advantage of the strong autofluorescence of amino-coupled GnP. ${ }^{37}$ Observations were carried out using a Zeiss Axio Scope A1 fluorescence microscope equipped with a TRITC filter.

Atomic force microscopy. Atomic force microscopy (AFM) topographical measurements were performed by using a PICOSPM setup (Molecular Imaging) equipped with silicon nitride cantilevers having a spring constant of $0.3 \mathrm{~N} \mathrm{~m}^{-1}$. AFM imaging was operated in contact mode at room temperature in wet conditions (Tris/ $\mathrm{NaCl}$ buffer). A low permanent contact force was used to avoid damage on the samples. Deflection and topography images were acquired simultaneously at a fixed scan rate of 1 line $\mathrm{s}^{-1}$ with a reso- lution of $512 \times 512$ pixels. Distinct samples were inspected before and after $\mathrm{AE}$, after LbL deposition, and after posttreatment with GnP. Micrographs were analyzed with the SPIP Software (Scanning Probe Image Processor) to determine the arithmetical mean roughness $(\mathrm{Ra})$ over $50 \times 50$ $\mu \mathrm{m}^{2}$ areas.

Static contact angle measurements. We assessed the wettability of all samples by measuring static contact angles with a Digidrop apparatus (GBX instruments - France). Before measurements, the samples were briefly rinsed with ultrapure water and dried by blowing argon. At least three $5-\mu \mathrm{L}$ drops of Tris/NaCl buffer were generated and deposited on each substrate using an automatic micrometric syringe. For each drop, the static contact angle was determined thrice semi-manually from an image captured by a digital camera $2 \mathrm{~s}$ after deposition.

\section{Cell culture conditions}

MC3T3-E1 pre-osteoblast cells (subclone 4) were used for the biological assessment of our substrates. Cells were routinely cultured with $\alpha$-MEM supplemented with $10 \%$ foetal bovine serum (FBS), $100 \mathrm{mg} \mathrm{mL}^{-1}$ streptomycin, $100 \mathrm{mM}$ penicillin, $2 \mathrm{mM}$ L-glutamine (standard culture medium) in $75 \mathrm{~cm}^{2}$ tissue culture flasks, and incubated in a humidified atmosphere with $5 \% \mathrm{CO} 2$ at $37^{\circ} \mathrm{C}$. When subconfluent, cells were enzymatically detached using $0.25 \%$ trypsin/1 $\mathrm{mM}$ EDTA.

\section{Cell morphology}

MC3T3-E1 pre-osteoblasts were seeded at a density of $2 \times$ $10^{4}$ cell $\mathrm{cm}^{-2}$ onto the substrates. After $3 \mathrm{~h}$, cells were rinsed with cold PBS, fixed with a $3 \%$ formaldehyde solution for $15 \mathrm{~min}$, permeabilized for $5 \mathrm{~min}$ in 1\% PBS-Triton X-100 and treated with 1\% PBS-BSA for 30 min. Then, cells were stained during $1 \mathrm{~h}$ for F-actin cytoskeleton with FITCconjugated phalloidin $\left(10 \mu \mathrm{g} \mathrm{m}^{-1}\right)$ and for nuclei with DAPI $\left(2.5 \mu \mathrm{g} \mathrm{mL}^{-1}\right)$. Finally, preparations were mounted with Mowiol 4-88 overnight at $+4^{\circ} \mathrm{C}$ and observed with a Zeiss Axio Scope A1 epifluorescence microscope.

\section{Cell proliferation}

MC3T3-E1 proliferation was indirectly assessed by using Alamar Blue ${ }^{\circledR}(\mathrm{AB})$ assay. $\mathrm{AB}$ assay is an oxidation-reduction indicator of the metabolic activity of viable cells during proliferation. Cells were seeded at a $1 \times 10^{4} \mathrm{cells}_{\mathrm{cm}}^{-2}$ density onto each substrate and cultured for 2 and 9 days (D2 and D9). At each time point, culture medium was replaced by a $10 \%(\mathrm{v} / \mathrm{v}) \mathrm{AB}$ containing culture medium for $4 \mathrm{~h}$ incubation. Then, absorbance was measured at 570 and $600 \mathrm{~nm}$ and the percentage of $\mathrm{AB}$ reduction was determined in accordance to the manufacturer's instructions.

\section{Pre-osteoblasts early/late differentiation}

For both early and late MC3T3-E1 differentiation, cells were seeded at a $5 \times 10^{4}$ cell $\mathrm{cm}^{-2}$ density in the standard culture medium. After 2 days, the medium was replaced by an osteogenic culture medium, i.e. standard medium 

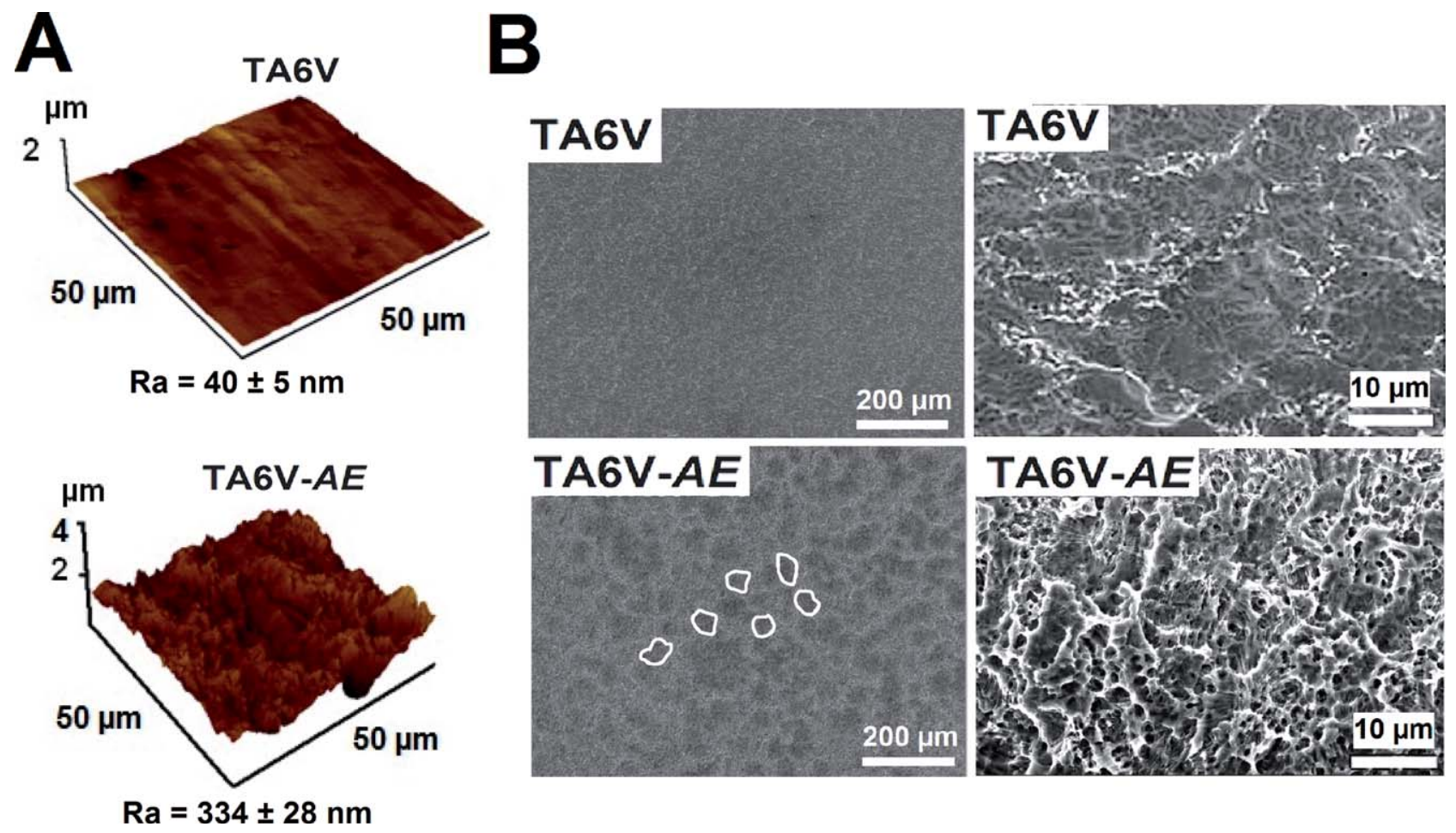

FIGURE 1. Surface analysis of Ti-6Al-4V substrates before (TA6V) and after (TA6V-AE) acid-etching (AE). (A) 3D AFM images. (B) SEM images at two magnifications. Surfaces were roughened upon AE treatment with bone-lacunae-like cavities of ca. 50-100 $\mu \mathrm{m}$ in size (white delimited areas-bottom left in B) and nanopits (bottom in A, and bottom right in B).

supplemented with $10 \mathrm{~m} M \beta$-glycerophosphate and $50 \mu \mathrm{g}$ $\mathrm{mL}^{-1}$ L-ascorbic acid-2-phosphate.

Alkaline phosphatase assay. Alkaline phosphatase (ALP) activity, an early marker for osteoblast differentiation, was determined for MC3T3-E1 cultured atop each substrate for 7 and 14 days (D7 and D14). At the desired time, cells were collected, subjected to three freeze-thaw cycles, and finally lysed with $0.1 \%$ Triton X-100. Then, ALP activity in cell lysates was determined by measuring the UV-Vis absorbance of p-nitrophenol yielded by ALP-induced hydrolysis of p-nitrophenol phosphate. Cell lysates were also used to quantify the total intracellular proteins with a micro-BCA protein kit (Pierce) in order to normalize ALP activity to total protein concentration.

Confocal Raman microspectroscopy. Mineralization of the osteoid, the organic extracellular matrix produced by osteoblasts, is a late marker for osteoblast maturation. Confocal Raman microspectroscopy was used (i) to identify the chemical nature of the calcium phosphate nodules and (ii) for chemical mapping of the mineralized areas. All the measurements were performed on dried samples. The setup was composed of a LabRam HR Raman spectrometer (Horiba Jobin-Yvon) with a 600 lines $\mathrm{mm}^{-1}$ grating coupled to a confocal microscope (Model BX41, Olympus) via optical fibers. The excitation of Raman scattering was operated with a helium-neon laser at a wavelength of $632.8 \mathrm{~nm}$. A confocal pinhole (diam. $250 \mu \mathrm{m}$ ) before the entrance slit rejected the Raman signal from out-of-focus planes. The laser beam was focused on the sample by means of a $\times 50$ LWD or a $\times 100$ microscope objective. Integration times were set to produce Raman spectra with good signal-to-noise ratio.

\section{Statistical analysis}

All surface characterizations and cell experiments were performed in triplicate and quantitative results were presented as mean \pm SEM. We applied the nonparametric Mann-Whitney-Wilcoxon test for comparisons between unrelated groups and significance level was assigned at $p<0.05$.

\section{RESULTS}

Surface characterization of bare and acid-etched substrates

AE had a strong impact on the TA6V substrates: (i) visually, they lost their metallic luster, (ii) their mass was reduced by ca. $4 \%$ upon dissolution, and (iii) they were much roughened as seen on AFM and SEM images (Fig. 1). Roughness values Ra derived from AFM data were varied over one order of magnitude in the biologically relevant range, from $40 \pm 5 \mathrm{~nm}$ for TA6V (in accordance with the supplier's data given in section "Substrates preparation and AE") to $334 \pm$ $28 \mathrm{~nm}$ for TA6V-AE. AFM [Fig. 1(A)] and highest magnification SEM [Fig. 1(B), right] analyses were consistent, showing relatively smooth surfaces for TA6V samples, and nanostructured morphologies with numerous submicrometric pits for TA6V- $A E$ samples. Interestingly, larger scale SEM images revealed periodic lateral micro-ranged cavities 

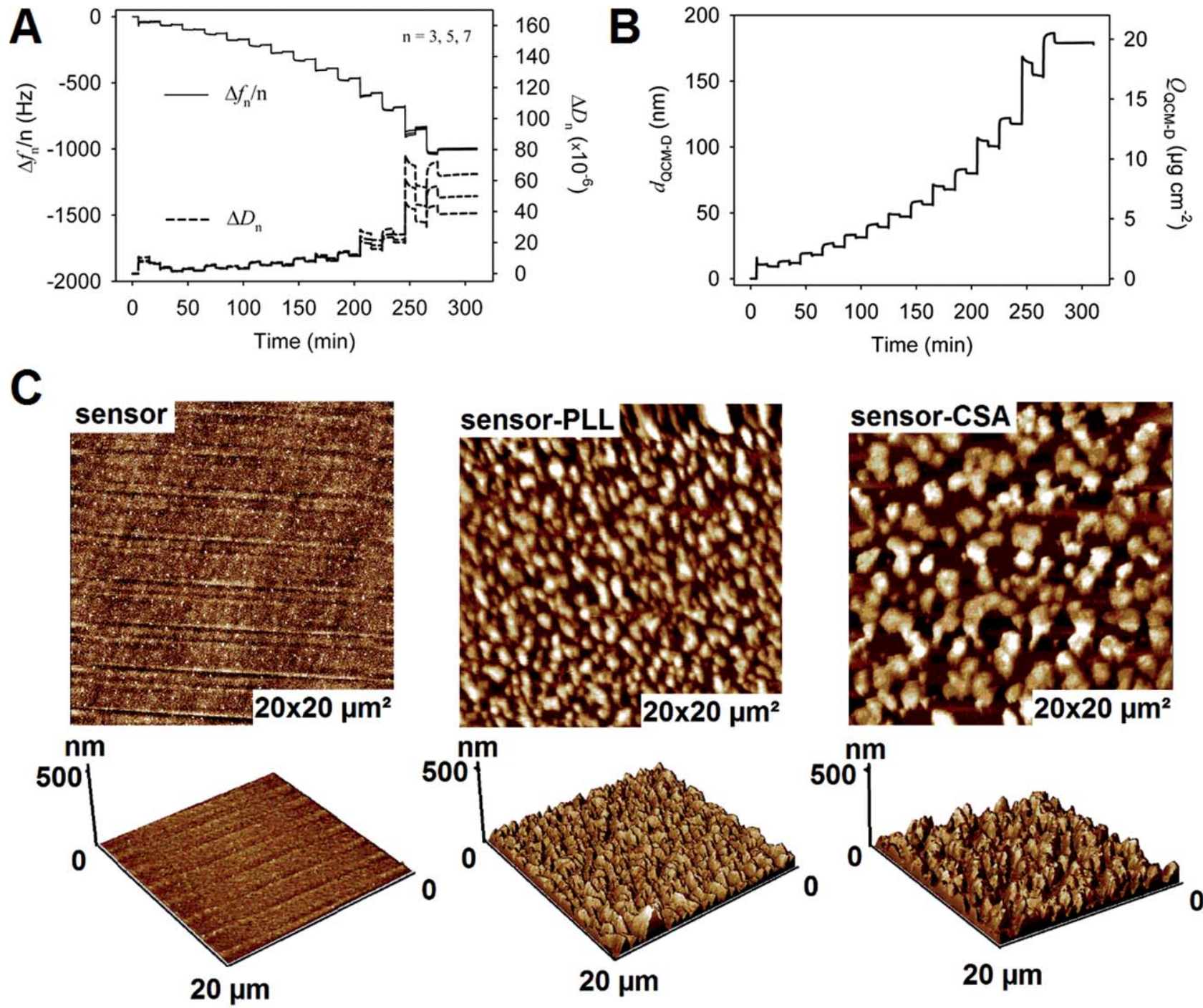

$\mathrm{Ra}=7 \pm 2 \mathrm{~nm}$
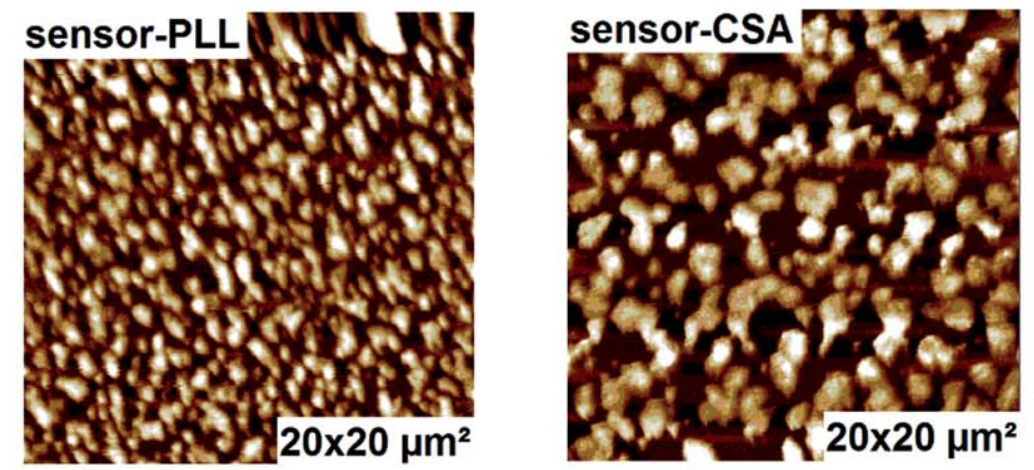

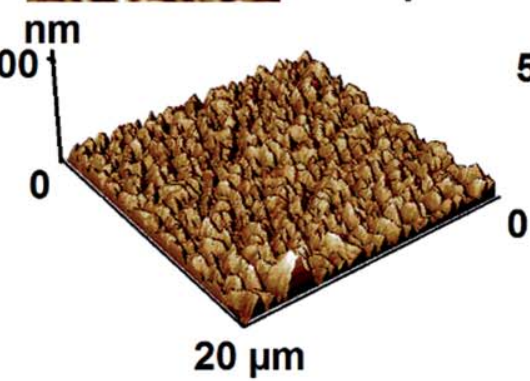

$\mathrm{Ra}=\mathbf{2 7} \pm \mathbf{5} \mathrm{nm}$

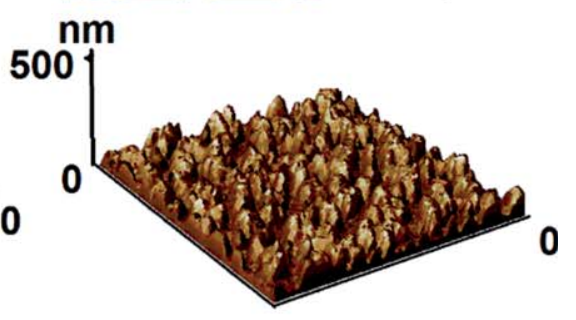

$20 \mu \mathrm{m}$

FIGURE 2. (A) Typical evolutions of the normalized resonance frequencies and dissipation factors for the 3rd, 5 th, and 7 th overtones $(n=3,5,7)$ during the buildup of a $\mathrm{PEI} /(\mathrm{CSA} / \mathrm{PLL})_{6} / \mathrm{CSA}$ film at $\mathrm{pH} 7.4$ and Tris/NaCl buffer (10 mM Tris, $150 \mathrm{mM} \mathrm{NaCl}$ ) onto a $\mathrm{QSX} 310 \mathrm{Ti}$-coated quartz crystal sensor. (B) Conversion of the raw data shown in (A) into hydrodynamic thickness $\mathrm{d}_{\mathrm{OCM}-\mathrm{D}}$ and hydrated mass $\mathrm{Q}_{\mathrm{QCM}-\mathrm{D}}$ according to the $\mathrm{V}_{\mathrm{O}} \mathrm{igt}$ viscoelastic model. (C) 2D and 3D AFM images of the Ti-coated OCM-D sensors before and after LbL film deposition: (left) bare sensor, (middle) $\mathrm{PEI} /(\mathrm{CSA} / \mathrm{PLL})_{6}$, (right) $\mathrm{PEI} /(\mathrm{CSA} / \mathrm{PLL})_{6} / \mathrm{CSA}$. Average roughness values Ra were derived from $50 \times 50 \mu \mathrm{m}^{2}$ areas.

(ca. 50-100 $\mu \mathrm{m}$ in size), uniformly distributed over AE-treated substrates [Fig. 1(B), bottom left), white-delimited areas.

\section{Surface characterization of LbL-coated TA6V and} TA6V-AE substrates

In previous works, we have extensively characterized the buildup mechanism and the structure of PEI/(CSA/PLL) $i$ (with $i$ the number of layer pairs) LbL films onto various substrates, ${ }^{23,31,38}$ but not onto Ti-based surfaces. Therefore, we validated the assembly of the films onto Ticoated QCM-D sensors viewed as more realistic models of our TA6V substrates than the Au-coated sensors used previously.

Figure 2(A and B) respectively show the corresponding variations of the raw QCM-D parameters, and their conver- sion into hydrodynamic thickness and adsorbed mass during the buildup of a typical PEI/(CSA/PLL) $6 /$ CSA film. We obtained an exponential growth regime during the building of LbL films. The hydrodynamic thickness and the hydrated mass of the films were about $180 \mathrm{~nm}$ and $20 \mu \mathrm{g} \mathrm{cm}^{2}$, respectively. Also, from the AFM data reported in Figure 2(C), the films displayed an islet-like topography.

We verified the presence and the uniformity of the precursor layer atop the TA6V and TA6V-AE substrates by using $\mathrm{PEI}^{\mathrm{FITC}}$. Fluorescence microscopy images reported in Figure 3 confirmed that the substrates were fully covered with the polymer, with apparently preserved topography for the AE samples (bottom-right image).

We then characterized the TA6V and TA6V-AE substrates after the deposition of $\mathrm{PEI} /(\mathrm{CSA} / \mathrm{PLL})_{6} \pm \mathrm{CSA}$ films and 

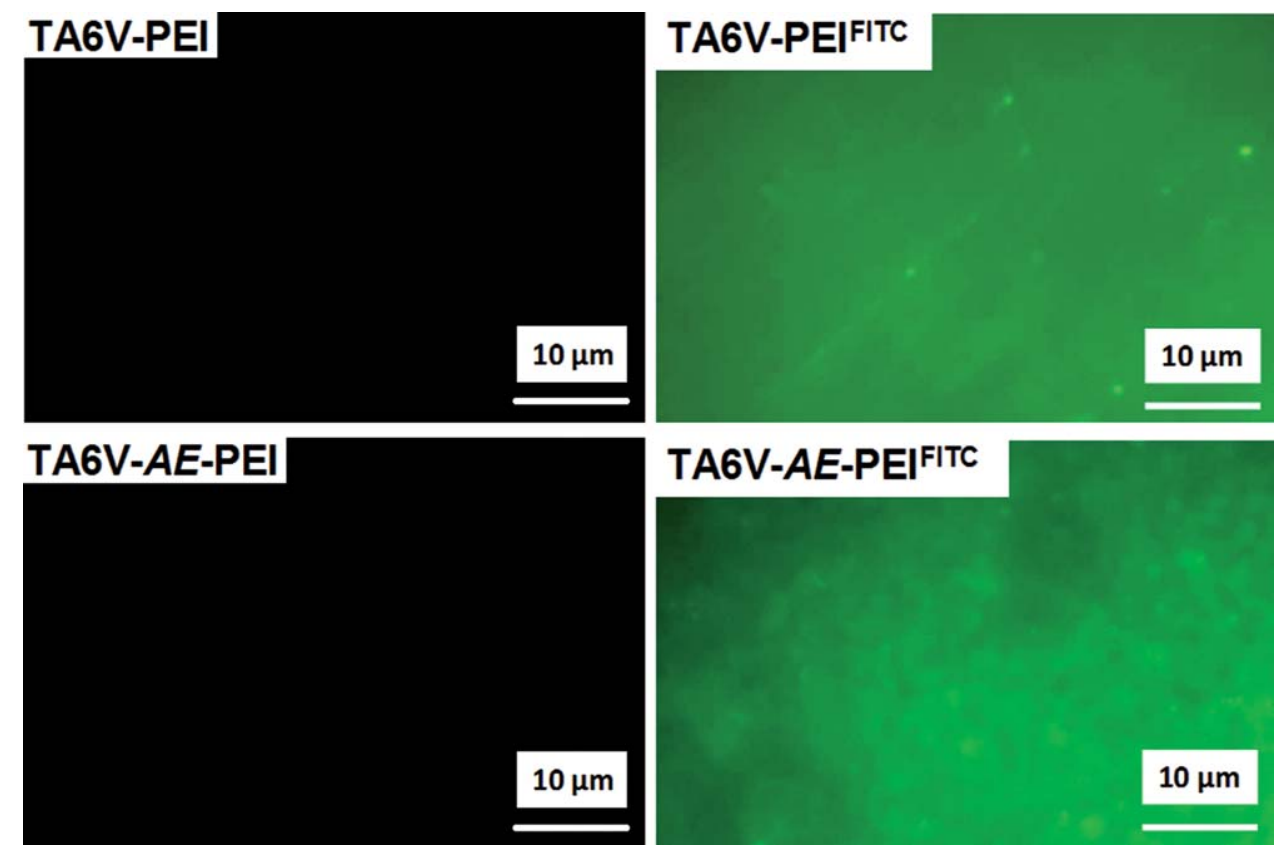

FIGURE 3. Fluorescence microscopy images of TA6V and TA6V-AE substrates coated with (left) PEI and (right) PEI ${ }^{\mathrm{FITC}}$. PEI ${ }^{\mathrm{FITC}}$ continuously covered the substrates.

after the post-treatment with GnP. From the typical islet-like topography observed on 2D AFM images [Fig. 4(A), top], TA6V substrates were homogeneously covered by LbL films. The presence of the films on TA6V-AE could not be evidenced by 2D AFM images because of the intrinsic roughness of the substrates. 3D AFM images [Fig. 4(A), bottom] and SEM images [Fig. 4(B)] showed that the dual topography of the substrates was maintained upon the deposition of LbL films, meaning that the polymers conformed to the surface, and did not fill up the pits and cavities. We also verified that the final topographies were similar whatever the CSA or PLL terminal layer of the films.
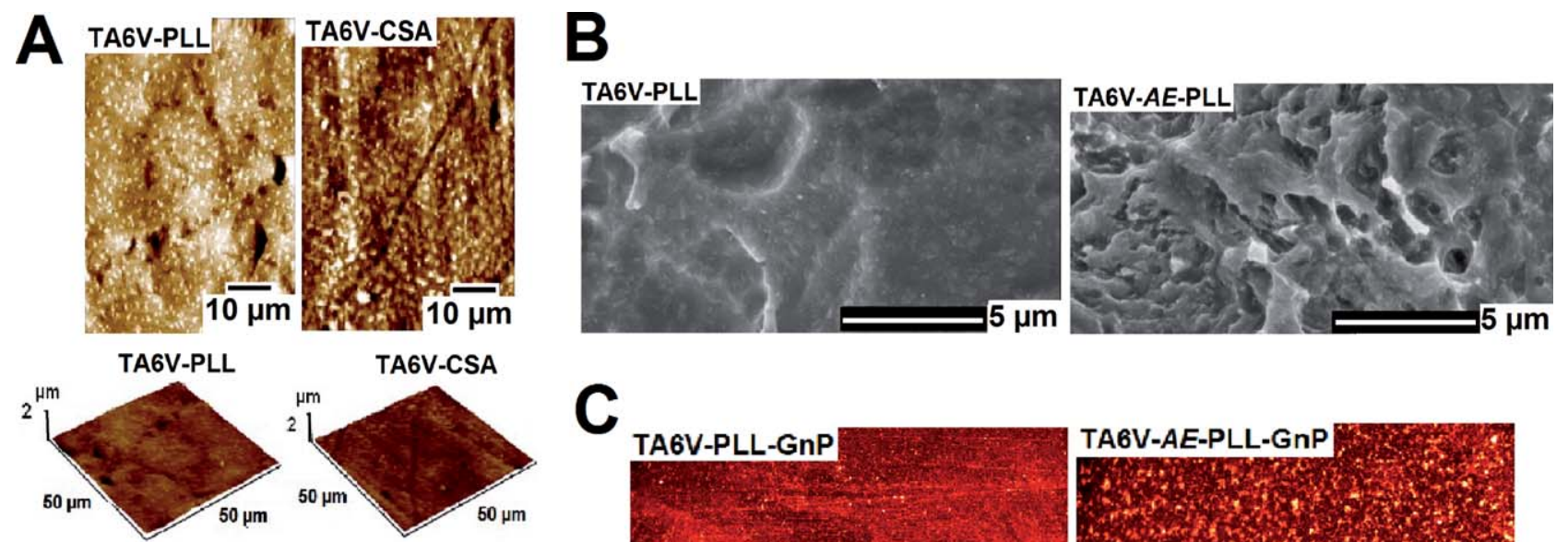

TA6V-AE-PLL
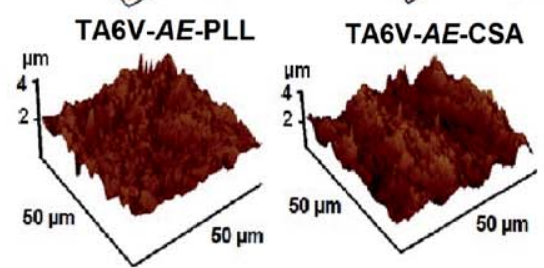

\section{.}

TA6V-PLL-GnP

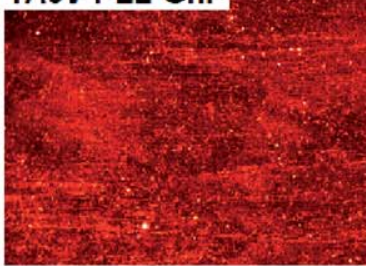

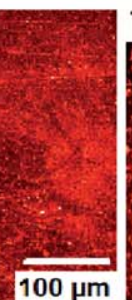

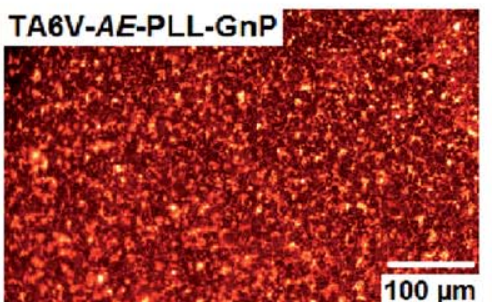

FIGURE 4. Qualitative surface characterization of the LbL-coated TA6V and TA6V-AE substrates. (A) 2D and 3D contact mode AFM micrographs in hydrated conditions after deposition of a $\mathrm{PEI} /(\mathrm{CSA} / \mathrm{PLL})_{6}$ or a $\mathrm{PEI} /(\mathrm{CSA} / \mathrm{PLL})_{6} / \mathrm{CSA}$ film. (B) SEM views of the former substrates. (C) Fluorescence microscopy images of $\mathrm{PEI} /(\mathrm{CSA} / \mathrm{PLL})_{6}$ films after treatment with GnP. Continuous LbL coatings were obtained, without alteration of the underlying topography. 
TA6V $\square \mathrm{TA6V}-\mathrm{AE}$

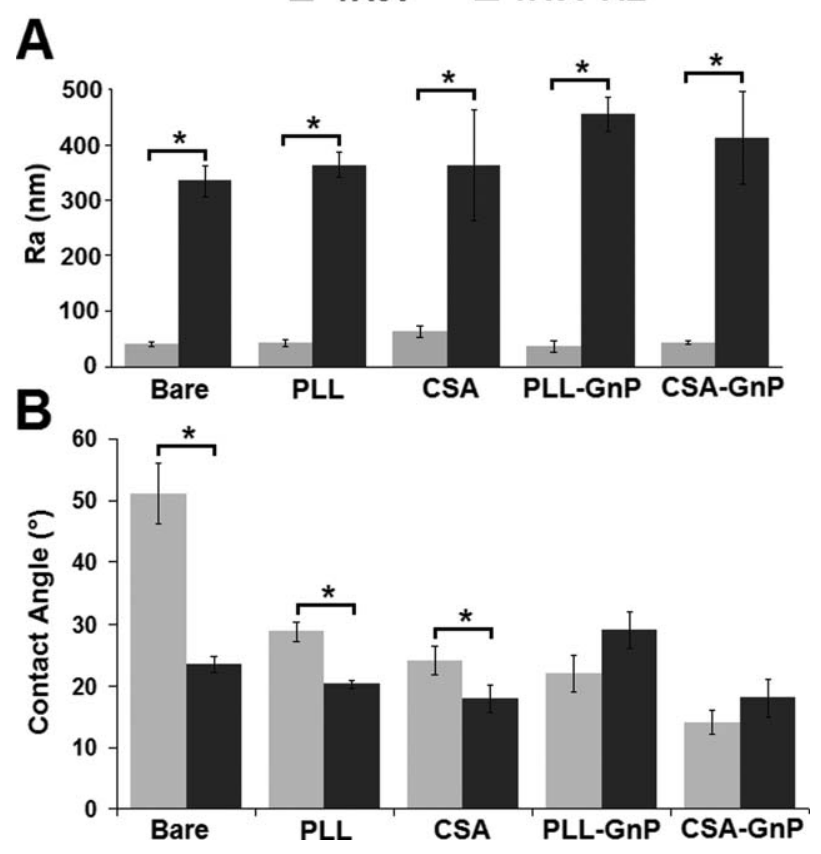

FIGURE 5. Quantitative surface characterization of bare and LbLcoated TA6V and TA6V-AE substrates. LbL films consisted in native and GnP-cross-linked PEI/(CSA/PLL) $6 \pm$ CSA architectures. (A) Average roughness $\mathrm{Ra}$ derived from $50 \times 50 \mu \mathrm{m}^{2}$ 2D AFM images. (B) Static contact angles measured with the Tris/ $\mathrm{NaCl}$ buffer ( $5 \mu \mathrm{L}$ droplets) at room temperature. Results were expressed in mean \pm SD. Statistical differences set for $p<0.05(*)$.

The strong autofluorescence of amino-coupled GnP [Fig. $4(\mathrm{C})]$ (i) showed that the cross-linking treatment of the films with $\mathrm{GnP}$ was successful, (ii) confirmed the continuous coverage of the substrates and (iii) corroborated that the desired topography combining nano- and microscale roughness, was preserved.

Figure 5(A) reports the average roughness $\mathrm{Ra}$ of the substrates, as derived from 2D AFM images. Similar values of 40-50 nm were measured for both bare and all LbLcoated TA6V, whereas values in the range 350-450 nm were obtained for the corresponding TA6V-AE substrates. The AE treatment clearly increased the hydrophilic character of the bare substrates, with contact angles decreased from $\sim 51^{\circ}$ to $\sim 23^{\circ}$ [Fig. 5(B)]. All the substrates coated with native LbL films had similar hydrophilic character, with contact angles between $20^{\circ}$ and $30^{\circ}$. A slight decrease of the wettability was observed after treatment of the LbL-coated substrates with GnP.

\section{Cell morphology}

For anchorage-dependent mammalian cells such as preosteoblasts, optimal adhesion is a required and crucial step prior to any subsequent cell process and even, for cell survival. Therefore we inspected the morphology, which is a direct indicator of the quality of adhesion, of MC3T3-E1 pre-osteoblast cells on top of our substrates. DAPI-labelled nuclei and FITC-phalloidin-labelled actin filaments organization were observed $3 \mathrm{~h}$ after seeding by means of epifluorescence microscopy (Fig. 6). Both bare TA6V and bare TA6V- $A E$ substrates were favorable to the adhesion of cells, as indicated by their mostly polygonal and well-spread morphology, with slight differences. Whereas cells exhibited a dense cortical actin network onto nano-rough TA6V, the actin network was rather diffuse atop nano/microrough TA6V-AE (Fig. 6, left). After $3 \mathrm{~h}$ of culture atop TA6V and
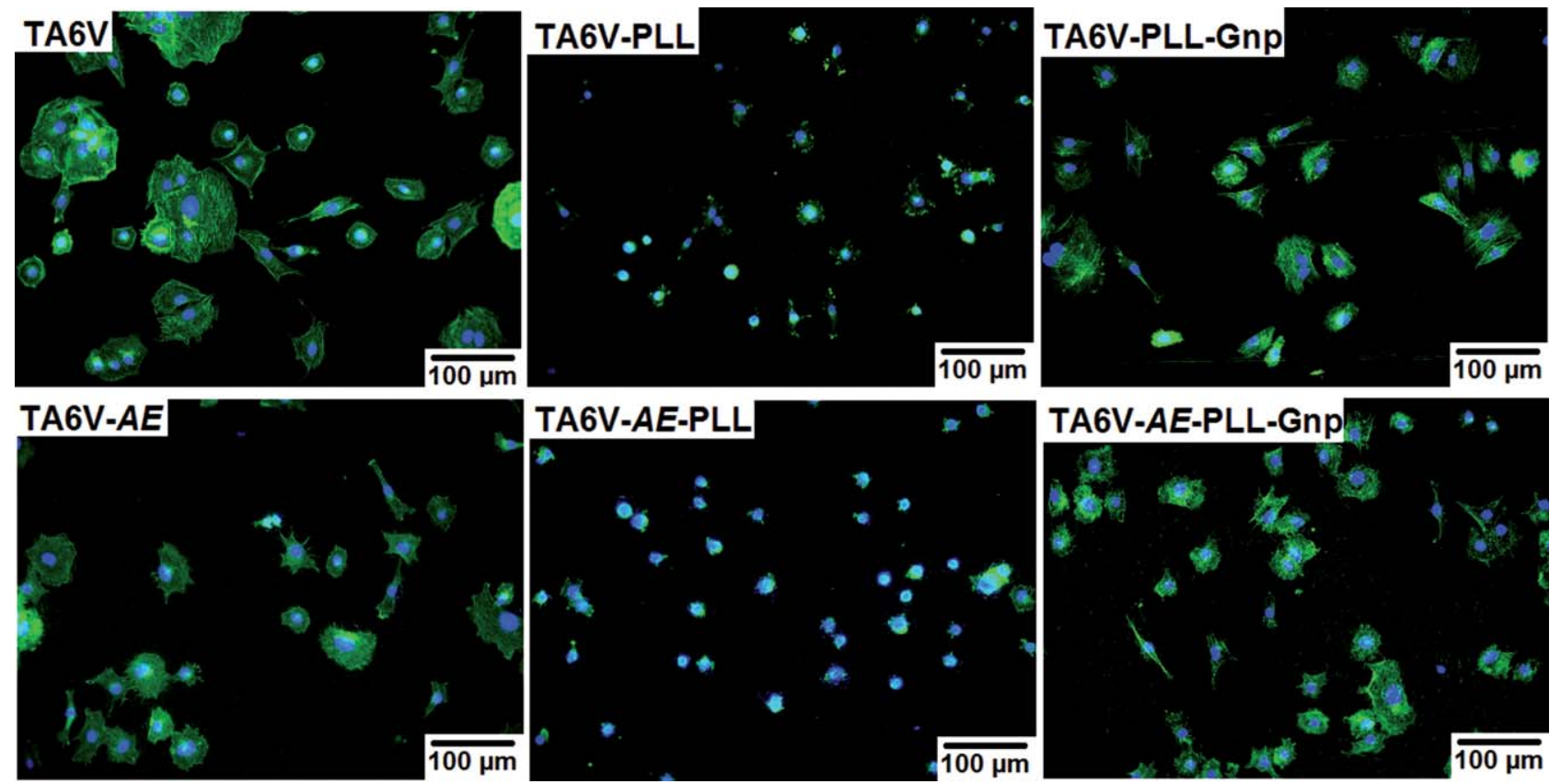

FIGURE 6. Morphology of MC3T3-E1 pre-osteoblasts cultured for $3 \mathrm{~h}$ onto bare and LbL-coated TA6V and TA6V-AE substrates as observed by epifluorescence of DAPI (nuclei) and FITC-phalloidin (actin). LbL films consisted in native and GnP-cross-linked PEI/(CSA/PLL) 6 architectures. Similar results were obtained with $\mathrm{PEI} /(\mathrm{CSA} / \mathrm{PLL})_{6} / \mathrm{CSA}$ architectures (see Supporting Information). 

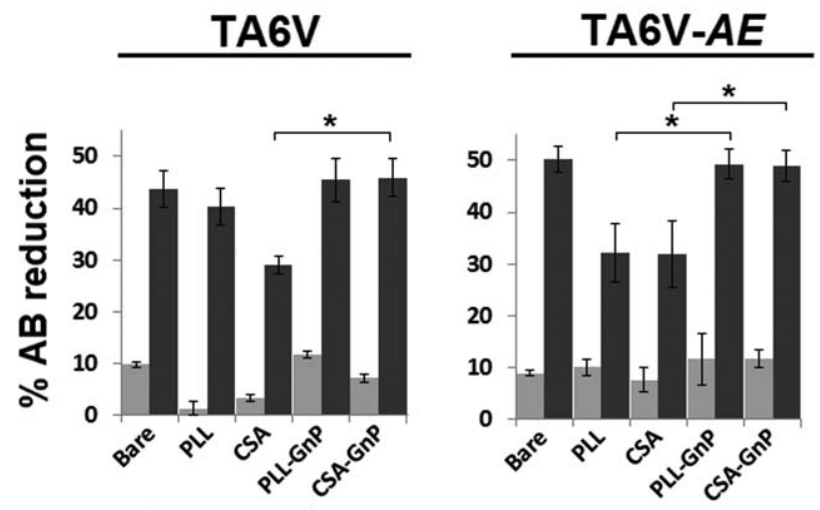

FIGURE 7. Proliferation of MC3T3-E1 pre-osteoblasts cultured for 9 days onto bare and LbL-coated TA6V and TA6V-AE substrates. LbL films consisted of native or GnP-cross-linked PEI/(CSA/PLL) $6 \pm$ CSA architectures. Alamar Blue $(A B)$ reduction was assayed after 2 days (D2) and 9 days (D9). The results are presented in \% of $A B$ reduction and expressed as mean \pm SEM. * $p<0.05$ with respect to the corresponding native LbL films.

TA6V-AE substrates coated with native (non-cross-linked) CSA/PLL LbL films, cells poorly adhered and remained rather rounded. In contrast, initial adhesion was much enhanced on top of the GnP-cross-linked films, leading to well-spread, polygonal cells with organized actin filament cytoskeleton, whatever the topography of the substrate and the nature of the outer, CSA or PLL layer. Contrary to bare substrates, there was no visible dependence of cell morphology on the outer layer of the film, indicating that the favorable mechanical properties provided by the treatment with GnP constituted the main factor of the cell adhesion improvement. At this stage, it comes out that cell adhesion was governed by a complex interplay of topography, chemistry, and mechanics of the substrates.

\section{Cell proliferation}

Proliferation of MC3T3-E1 cells was assessed indirectly by using the Alamar Blue (AB) assay at D2 and D9 (Fig. 7). Consistently with the cell adhesion data, AE treatment had little impact on cell proliferation in the absence of LbL films, whereas native CSA/PLL films strongly reduced the cell proliferation at short-term (D2) on top of TA6V. Surprisingly, the proliferation at D2 on top of AE substrates coated with native films was unaffected despite poor initial adhesion. At longer term (D9), the native films were less favorable to cell proliferation than the bare substrates. In line with cell adhesion data, cell growth at both short and long terms were fully preserved on top of GnP-stiffened films whatever the underlying topography.

\section{Cell differentiation}

We inspected the potential osteoconductive properties of our substrates at early (D7, D14) and late (5 weeks) stages. MC3T3-E1 cells were plated at a high cell density $\left(5 \times 10^{4}\right.$ cell $\mathrm{cm}^{-2}$ ) in order to reduce their proliferation, and subsequently, to favor their differentiation. They were cultured in a minimal osteogenic medium (ascorbic acid and $\beta$ glycerophosphate).

We followed the cultures over 14 days and ALP was assayed at D7 and D14 [Fig. 8(A)]. The ALP activity was clearly decreased by ca. $50 \%$ atop bare TA6V-AE compared to bare TA6V. The ALP activity was still more dramatically reduced on top of native LbL films, consistently with the previous data showing that cell processes are impaired by native LbL films. In the presence of GnP-cross-linked films, the ALP activity at D7 was far less decreased on TA6V, and was clearly enhanced on TA6V-AE compared to the corresponding bare substrates. For all the substrates, we could thus almost preserve the potential of differentiation induction of bare TA6V as far as the LbL films were GnP-crosslinked. For most of the substrates, we noted an overall reduction of ALP activity at D14. As a result, the optimal substrates for early differentiation were the TA6V-AE substrates covered with GnP-treated LbL films whatever the ending layer, and the TA6V substrates covered with CSAending, but not PLL-ending, GnP-treated LbL films.

Next, we inspected the capability of MC3T3-E1 to mineralize their organic extracellular matrix (osteoid) atop TA6V and TA6V- $A E$ substrates coated with GnP-treated films, by means of Raman microspectroscopy analyses, after 5 weeks of culture. Importantly, to ascertain that the detected mineralization was exclusively cell-mediated, we immersed a series of acellular substrates in the same osteogenic culture medium as that for cell-seeded ones. Indeed, it has been shown that the presence of $\beta$-glycerophosphate ( $\beta$-GP) in the culture medium could induce a non-cell-mediated mineral precipitation because of the cleavage of phosphate from $\beta-\mathrm{GP}^{39}$ Whereas no mineralization was observed in the absence of cells, we detected the presence of (i) sparse mineralized nodules with Raman signatures containing the $v_{1}$ $\mathrm{PO}_{4} 3$ - (major band), $v_{2} \mathrm{PO}_{4}^{3}, v_{3} \mathrm{PO}_{4}^{3-}, v_{4} \mathrm{PO}_{4}^{3-}$, and $v_{1} \mathrm{CO}_{3} 2-$ $\left(1070 \mathrm{~cm}^{-1}\right)$ bands related to B-type carbonated hydroxyapatite (HA), that is the major mineral phase of the mineralized ECM produced by mature osteoblasts [Fig. 8(B-a)], and (ii) a uniform underlying ECM, characterized by the intense symmetric ring breathing Raman band of phenylalanine at $1003 \mathrm{~cm}^{-1}$ [Fig. 8(B-b)].

As a first approach to compare the potentials of the various substrates in terms of late mineralization induction, we thoroughly explored their surface to localize the largest mineralized nodules. We then established chemical mappings of the corresponding areas, by following the intensity of the major specific band of HA at $960 \mathrm{~cm}^{-1}$ [Fig. 8(C)], and we compared the morphologies and sizes of the nodules. The largest and most uniform cell-induced HA deposits were detected on top of the AE substrates coated with GnPtreated LbL films, which were thus confirmed as the best promoters of late osteogenic differentiation.

\section{DISCUSSION}

In this study, we proposed biomimetic surface modifications of TA6V by combining (i) topomimetic features that imitate bone surface cavities left after osteoclast resorption and (ii) 
A

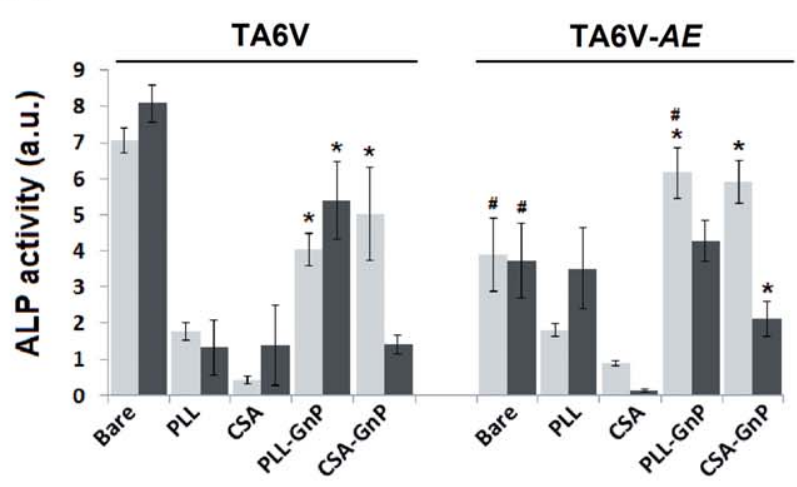

C

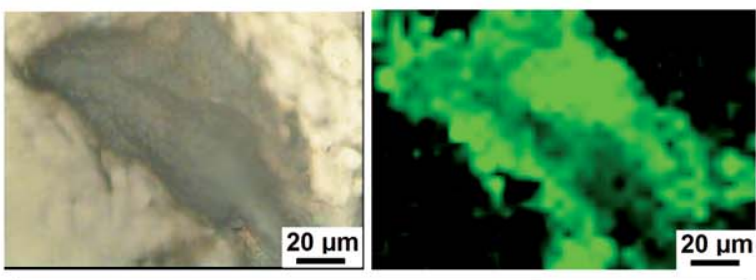

TA6V-CSA-GnP

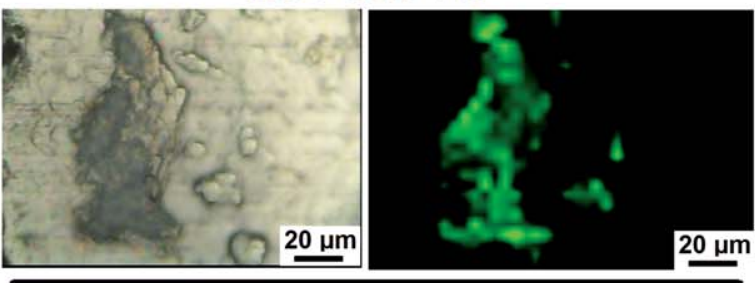

TA6V-PLL-GnP
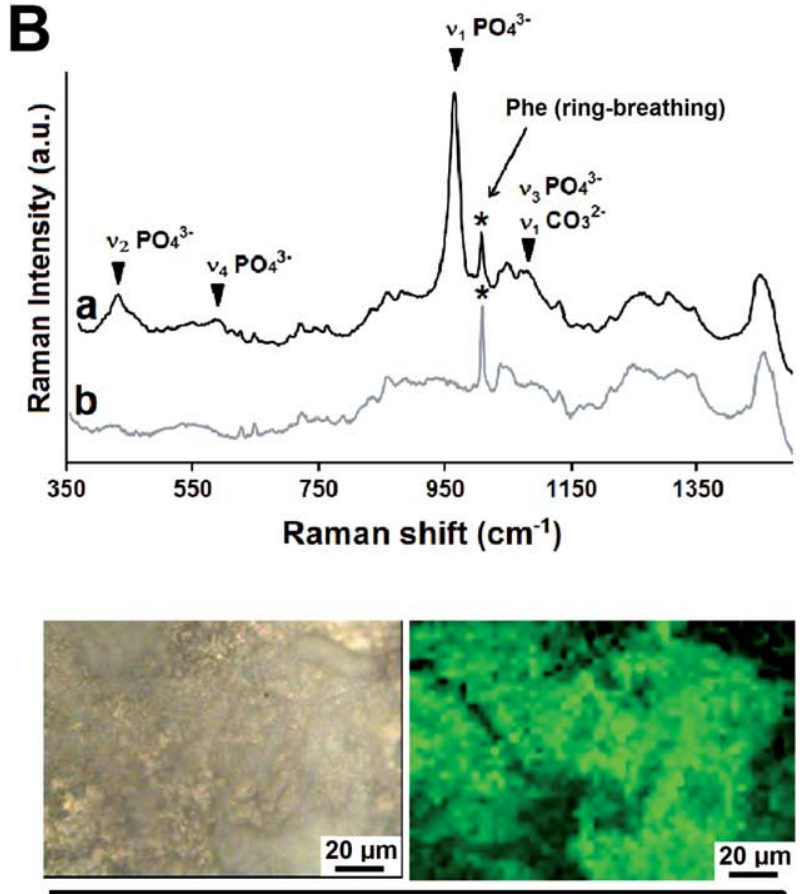

TA6V-AE-CSA-GnP

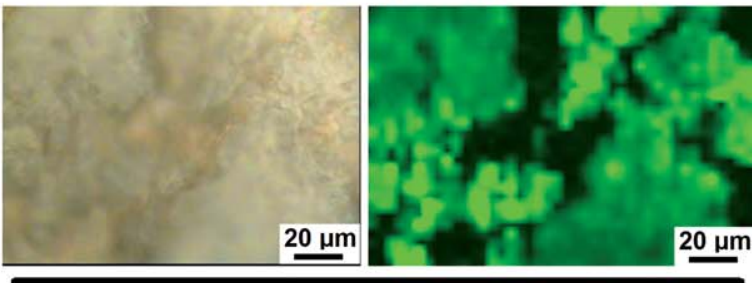

TA6V-AE-PLL-GnP

FIGURE 8. Early and late differentiation of MC3T3-E1 cultured in an osteogenic culture medium. (A) ALP activity for cells cultured atop bare (TA6V) and acid-etched (TA6V-AE) substrates, coated with PEI-(CSA/PLL) 6 or PEI-(CSA/PLL) 6 -CSA (noted -PLL and -CSA respectively) in their native state or cross-linked with $\mathrm{GnP}$ (noted $-\mathrm{GnP}$ ). ALP was assayed at D7 and D14. Results are presented as mean \pm SD. * $p<0.05$ with respect to the corresponding native LbL films. \# $p<0.05$ with respect to the corresponding non-AE substrates. (B) Typical Raman spectra of (a) the mineralized nodules found atop AE substrates coated with GnP-treated films and (b) the extracellular matrix produced cells. The major Raman bands associated with hydroxyapatite are assigned by arrow heads and phenylalanine (Phe, ring breathing) by an asterisk. (C) Corresponding optical micrographs and 2D Raman spectral mapping (in green) of the band $v 1 \mathrm{PO}_{4}{ }^{3}-$ at $960 \mathrm{~cm}^{-1}$.

ECM-mimetic LbL films that involve chondroitin sulfate A. Such a combination revealed a promising strategy that preserved the intrinsic osteoconductive properties of TA6V and that would improve its osteogenic potential since the adsorbed LbL films will ultimately serve as reservoirs for local delivery of bioactive compound. ${ }^{40,41}$

Surface topography of an implant is one of the key parameters affecting cellular events that has been investigated for long, for improving bone bonding. Some recent papers reported patterned surfaces exhibiting well-defined geometries (grooves, ridges, pits, posts, pillars or stars...) to assess cell behavior from various lineages, ${ }^{42,43}$ while some others proposed more physiologically relevant surfaces with biologically inspired features (nano/microfibrils, combined nano/microroughness...) mimicking the topography and the roughness of the natural tissues for tissue engineering purpose. ${ }^{44,45}$

Here, by $\mathrm{AE} \mathrm{TA} 6 \mathrm{~V}$, we generated uniformly distributed periodic lateral microscaled cavities with combined nano and microscaled features. As explained by Variola et al. ${ }^{11}$ such coexistence of nano and microtextures must result from different rates of etching for the $\alpha$ - and $\beta$-grains composing the TA6V alloy: etching of $\alpha$-grains produces "nanopits", while more readily etching of $\beta$-grains leads to both nanopits and large cavities. This dual topography closely resembles the complex morphology of osteoclast resorption depressions ${ }^{46}$ (known as Howship's lacunae), which constitute the natural microenvironment of osteoblasts during bone remodelling. ${ }^{47}$ Therefore TA6V-AE substrates appeared of particular relevance in view of the activation of osteoblast cells at implant surfaces.

We did not explore possible AE-induced chemical modification of the TA6V surface. It has been shown that AE treatment starts with the dissolution of the external passive oxide layer and then converts the underlying metallic Ti into titanium hydride $\mathrm{TiH}_{2}{ }^{48}$ We assume that the subsequent uniform coverage of surfaces by LbL films should limit the impact of such chemical variations on cells behavior. 
To validate the possible buildup of PEI/(CSA/PLL) 6 /CSA LbL films atop Ti-based surfaces and to characterize their physico-chemical structure, we used Ti-coated QCM-D sensors. We obtained very similar dimensions and viscoelastic character to films described onto Au-coated sensors. ${ }^{38}$ These films displayed islet-like topography as those built up previously onto smooth PDMS and glass substrates (Ra $30 \mathrm{~nm}){ }^{23,38}$ These data confirmed that the structure of $\mathrm{PEI} /(\mathrm{CSA} / \mathrm{PLL})_{6} \pm \mathrm{CSA}$ films was maintained whatever the chemical nature of the underlying substrate, certainly because of the use of a PEI precursor layer. Trybała et al. ${ }^{49}$ reported that a continuous precursor layer of branched PEI formed an anchoring network that allows the standardization of almost any surface material. We then checked that all our substrates were fully covered with the PEI polymer and preserved the topography for the AE samples. Based on these control experiments, we assumed that subsequent LbL coatings should have the same structural features atop our Ti-based substrates as onto the other PEI-activated substrates previously inspected.

Native CSA-containing LbL films are known to be cellrepellent because of very low elasticity. ${ }^{31,50}$ Therefore, we stiffened the films with genipin, a biocompatible natural cross-linking agent. ${ }^{51}$ In our previous work, we were able to measure the surface elastic moduli of similar cross-linked films built up onto flat glass slides by AFM nanoindentation and we ascertained that the GnP treatment stiffened the films. ${ }^{31}$ Here, we could not perform such measurements because of the substrate roughness, but we can reasonably assume that our surfaces were similarly stiffened upon the GnP treatment. Genipin treatment of (CSA/PLL)based LbL films would likely generate semi-IPN architectures since it reacts with amino-containing components, which is the case for PLL. Therefore, GnP would likely produce a cross-linked PLL-GnP network in which CSA molecules are free to diffuse. We assumed that these semi-IPNs would provide biomimetic rheological properties since the natural cell micro-environment is composed of interlaced self-assembled biopolymers. ${ }^{52}$

The roughness obtained for our substrates provided quantitative confirmation that LbL coatings and further GnP treatment did not alter the desired topographies and conformed the surfaces. Also, AE treatments rendered the bare surfaces hydrophilic. This is consistent with the Wenzel model supporting that there is a threshold of $90^{\circ}$ below which an increase of roughness increases the surface wettability and above which a converse effect is observed. ${ }^{53}$ All the substrates coated with native LbL films had similar contact angles which is in accordance with a previous work reporting a decrease of the contact angle of Ti-based substrates upon coating PLL or other polyelectrolytes. ${ }^{54} \mathrm{We}$ noted a slight decrease of the wettability after GnP treatment possibly because of the conversion of primary amines into more hydrophobic tertiary amines upon their coupling to $\mathrm{GnP}^{55}$ Overall, all the LbL-coated substrates were hydrophilic and thus, likely favorable to cell adhesion, as surfaces with water contact angles below $60^{\circ}$ are known to promote cell adhesion. ${ }^{56}$
Although the influence of topography onto short-term cell events like adhesion remains to be fully elucidated, it was already much documented in the literature. Generally, nanotextured surfaces were reported to promote the cytoskeleton and membrane receptors organization, ${ }^{57}$ whereas microtextured surfaces can withdraw the favorable effects of nanofeatures on cell adhesion. ${ }^{58}$ Our results were rather consistent with this general scheme since the cortical actin network of MC3T3-E1 cells cultured onto nanorough TA6V was dense while atop nano/microrough TA6V- $A E$, cells exhibited a rather diffuse actin network. When the Ti-based substrates were covered with native LbL films, we observed a poor cell adhesion with rather rounded cells. These results were somewhat expected since GAG-containing films are known to be highly hydrated particularly because of the presence of CSA that can bind up to 30 water molecules per disaccharide unit. $^{59}$ Of note, GAGs represent a few part of ECM by mass $(\sim 5 \%)$, but they turn into hydrogels when they are hydrated, representing $\sim 70 \%$ volume of the ECM. ${ }^{60}$ Therefore, CSA-containing LbL films display poor mechanical properties. In addition, as a polyanion, CSA exhibits negatively charged moieties that are exposed to negatively charged cell membrane, likely generating repulsive interactions. Although polycationic PLL is known to favor cell adhesion through electrostatic interactions, one can note here, that cell adhesion was not improved by PLLending, compared to CSA-ending films, which suggests that film hydration was the main factor of the poor initial adhesion observed. Yet, we previously reported that, despite similar limited anchoring at initial stage, MC3T3-E1 cells managed to adhere onto CSA/PLL LbL films at longer term. $^{23}$

As anticipated, the post-treatment of the films with genipin clearly improved cell adhesion with well-spread cells exhibiting a typical polygonal osteogenic morphology. Indeed, the intrinsic mechanical properties of such semi-IPN films likely matched those that pre-osteoblasts experience in their natural micro-environment. It is well admitted that the matrix stiffness can direct lineage specification of mesenchymal stem cells. ${ }^{61-64}$ In this line, anchoring cells and osteoblasts in particular, must adhere to mechanobiological relevant ECM-like substrates to survive and to preserve their phenotype and not de/trans-differentiate. Cell-ECM interactions are mainly mediated by integrins that translate external mechanical signals (i.e. the matrix stiffness), through the membrane, to intracellular actin-binding molecules. In particular, cells probe their mechanical environment by pulling on it and adapt accordingly by modulating their cytoskeleton. Stiff microenvironments exert resistance to cellular traction that leads to intracellular actin selfassembly and consequently, generates stress fibers that transmit the external mechanical signals to nucleus to direct lineage specification of cells. As a result, cells differentiate according to a mechanotransduction process that is matrix stiffness-dependent, which was probably the case for MC3T3-E1 in the present work. Proliferation of MC3T3-E1 cells was investigated over 9 days of culture in a standard culture medium. In line with cell adhesion data and with 
our previous work, ${ }^{31}$ cell growth at both short and midterms were fully preserved on top of GnP-stiffened films whatever the underlying topography. Altogether, these results highlighted that (i) the substrate stiffness was the major factor governing the initial (adhesion at $3 \mathrm{~h}$ ) and long term (proliferation at D9) cell behavior, (ii) the topography remained a minor factor, as it controlled only intermediately (at D2) the proliferation of cells on top of the native LbL films, while (iii) no clear effect of the surface chemistry could be detected.

Alkaline phosphatase (ALP) is a dephosphorylating enzyme, commonly used as an early marker of osteoblast maturation, necessary for the ultimate mineralization of the osteoid. ${ }^{65}$ ALP activity first increases during the differentiation induction step, and then decreases when the mature osteoblasts initiate mineralization of the osteoid. In this work, we observed that ALP activity was decreased atop bare TA6V-AE compared to bare TA6V. This is in accordance with others works reporting a reduction of ALP activity for osteoblasts cultured atop AE Ti-based substrates. ${ }^{54,66}$ In the presence of LbL films, we could preserve the potential of differentiation induction of bare TA6V as far as the LbL films were GnP-cross-linked. Furthermore, the overall reduction of ALP activity at D14 indicated the progress of preosteoblasts toward the mineralization induction phase.

Acid-etched TA6V substrates coated with GnP-treated LbL films were the best promoters of late osteogenic differentiation as they displayed the largest and most uniform HA deposits. Other works also reported enhanced differentiation of osteoblasts on top of substrates combining nanoand microscaled roughness. ${ }^{9,66}$ Based on the work of Zinger et al. reporting that osteoblasts aggregated within $100 \mu \mathrm{m}$ cavities of sand blasted/acid-etched substrates, ${ }^{47}$ we assumed that cells might have clustered within the topomimetic depressions generated by the AE treatment, mimicking the Howship's lacunae-like cavities that are left by osteoclasts, favoring cell-cell interactions required for cell differentiation. Also, the presence of CSA in our LbL coatings might have promoted the maturation of MC3T3-E1, as was the case on Ti-based implants coated with chondroitin sulfate and collagen. ${ }^{17}$

Noteworthy, we also analyzed our substrates with the current and widely used Von Kossa method to stain the extent of mineralization. But, this method reveals all calcium-containing deposits, and not specifically calcium phosphates. Indeed, by Raman microspectroscopy, we detected some calcium oxalate $(\mathrm{CaOx})$ deposits sequestered in the extracellular matrix, originating from the foetal bovine serum added in the culture medium. We evidenced the specific peaks of weddelite (dehydrated $\mathrm{CaOx}$ ) and whewellite (monohydrated CaOx) at $1468 \mathrm{~cm}^{-1}$ for $1493 \mathrm{~cm}^{-1}$, respectively. Therefore the results of Von Kossa staining were not enough reliable to be reported here. Generally, we consider that Raman microspectroscopy is a more accurate technique than the common nonspecific Von Kossa or Alizarin Red calcium staining methods, which may overestimate the extent of mineralization and even, retrieve false positives. ${ }^{67,68}$

\section{CONCLUSION}

In this work, by using $\mathrm{AE}$, we generated topomimetic surfaces of TA6V substrates exhibiting cavities that are bioinspired from Howship's lacunas with global microsized and local nanosized features. Then, by coating these substrates with CSA-based LbL films, we produced physiologically relevant surfaces, mimicking organic extracellular matrix of bone. Whereas short- and mid-term MC3T3-E1 events (adhesion and proliferation) were governed mainly by the stiffness of the substrate with a clear promotive effect of GnP-cross-linked films, the main factor of long-term cell differentiation on these films was the topography of the underlying substrate, with improved osteoconductive properties of the nano- and microtextured acid-etched TA6V compared to pristine TA6V.

As a whole, the nano/microtopography and chondroitin sulfate-based LbL films acted synergistically to preserve osteogenic properties of TA6V substrates. Even though no crucial influence of the nature of the outer CSA or PLL layer was detected, the potential of the LbL architectures as reservoirs of endogenous molecules or exogenous bioactive compounds and therapeutics (growth factors, antiinflammatory or bactericidal drugs) opens a promising route toward further sophisticated implants allowing the optimization the osseointegration processes.

\section{ACKNOWLEDGMENTS}

This work was partially supported by the Grand Évreux Agglomération (GEA) and the Conseil Général de l'Eure, France. The authors want to thank Beatrice Foulon (GPMCNRS UMR 6634, University of Rouen, France) for her help in the cutting of TA6V foils and also the License and Master students who have been involved in this work, in a way or another (Jeremy Beloncle, Helena Abed and Soror Mahieddine).

\section{REFERENCES}

1. Sykaras N, lacopino AM, Marker VA, Triplett RG, Woody RD. Implant materials, designs, and surface topographies: Their effect on osseointegration. A literature review. Int J Oral Maxillofac Implants 2000; 15:675-690.

2. Anselme K, Bigerelle M. Statistical demonstration of the relative effect of surface chemistry and roughness on human osteoblast short-term adhesion. J Mater Sci Mater Med 2006; 17:471-479.

3. Giordano C, Sandrini E, Busini V, Chiesa R, Fumagalli G, Giavaresi G, Fini R, Giardino A, Cigada A. A new chemical etching process to improve endosseous implant osseointegration: In vitro evaluation on human osteoblast-like cells. Int J Artif Organs 2006; 29:772-780.

4. Wennerberg A, Albrektsson T. Effects of titanium surface topography on bone integration: A systematic review. Clin Oral Implants Res 2009; 20:172-184.

5. Ergun C, Liu H, Halloran JW, Webster TJ. Increased osteoblast adhesion on nanograined hydroxyapatite and tricalcium phosphate containing calcium titanate. J Biomed Mater Res 2007; 80: 990-997.

6. de Oliveira PT, Zalzal SF, Beloti MM, Rosa AL, Nanci A. Enhancement of in vitro osteogenesis on titanium by chemically produced nanotopography. J Biomed Mater Res 2007; 80:554-564.

7. Gough JE, Notingher I, Hench LL. Osteoblast attachment and mineralized nodule formation on rough and smooth $45 \mathrm{~S} 5$ bioactive glass monoliths. J Biomed Mater Res 2004; 68:640-650.

8. Zhao G, Raines AL, Wieland M, Schwartz Z, Boyan BD. Requirement for both micron- and submicron scale structure for 
synergistic responses of osteoblasts to substrate surface energy and topography. Biomaterials 2007; 28:2821-2829.

9. Gittens RA, McLachlan T, Olivares-Navarrete R, Cai Y, Berner S, Tannenbaum R, Schwartz Z, Sandhage KH, Boyan BD. The effects of combined micron-/submicron-scale surface roughness and nanoscale features on cell proliferation and differentiation. Biomaterials $2011 ; 32: 3395-3403$.

10. Mustafa K, Wennerberg A, Wroblewski J, Hultenby K, Lopez BS, Arvidson K. Determining optimal surface roughness of $\mathrm{TiO} 2$ blasted titanium implant material for attachment, proliferation and differentiation of cells derived from human mandibular alveolar bone. Clin Oral Implants Res 2001; 12:515-525.

11. Variola F, Yi JH, Richert L, Wuest JD, Rosei F, Nanci A. Tailoring the surface properties of Ti6Al4V by controlled chemical oxidation. Biomaterials 2008; 29:1285-1298.

12. Becker D, Geissler U, Hempel U, Bierbaum S, Scharnweber D, Worch $\mathrm{H}$, Wenzel KW. Proliferation and differentiation of rat calvarial osteoblasts on type I collagen-coated titanium alloy. J Biomed Mater Res 2002; 59:516-527.

13. Kroese-Deutman HC, Van Den Dolder J, Spauwen PHM, Jansen JA. Influence of RGD-loaded titanium implants on bone formation in vivo. Tissue Eng 2005; 11:1867-1875.

14. Ruoslahti E, Yamaguchi Y. Proteoglycans as modulators of growth factor activities. Cell 1991; 64:867-869.

15. Ayukawa $Y$, Takeshita F, Inoue T, Yoshinari M, Ohtsuka Y, Murai K, Shimono M, Suetsugu T. An ultrastructural study of the bonetitanium interface using pure titanium-coated plastic and pure titanium rod implants. Acta Histochem 1996; 29:243-254.

16. Hoshi K, Ejiri S, Ozawa H. Localizational alterations of calcium, phosphorus, and calcification-related organics such as proteoglycans and alkaline phosphatase during bone calcification. J Bone Miner Res 2001; 16:289-298.

17. Bierbaum S, Douglas T, Hanke T, Scharnweber D, Tippelt S, Monsees TK, Funk RH, Worch $\mathrm{H}$. Collageneous matrix coatings on titanium implants modified with decorin and chondroitin sulfate: Characterization and influence on osteoblastic cells. J Biomed Mater Res A 2006; 77:551-562.

18. Miyasazi T, Miyauchi S, Tawada A, Anada T, Matsuzaka S, Suzuki O. Oversulfated chondroitin sulfate-E binds to BMP-4 and enhances osteoblast differentiation. J Cell Physiol 2008; 217:769777.

19. Decher G. Fuzzy nanoassemblies: Toward layered polymeric multicomposites. Science 1997; 277:1232-1237.

20. Hu Y, Cai K, Luo Z, Zhang Y, Li L, Lai M, Hou Y, Huang Y, Li J, Ding $X$, Zhang $B$, Sung $K L$. Regulation of the differentiation of mesenchymal stem cells in vitro and osteogenesis in vivo by microenvironmental modification of titanium alloy surfaces. Biomaterials 2012; 33:3515-3528.

21. Huang $Y$, Luo $Q$, Li X, Zhang F, Zhao S. Fabrication and in vitro evaluation of the collagen/hyaluronic acid PEM coating crosslinked with functionalized RGD peptide on titanium. Acta Biomater 2012; 8:866-877. DOI:10.1016/j.actbio.2011.10.020

22. Pavlukhina S, Sukhishvili S. Polymer assemblies for controlled delivery of bioactive molecules from surfaces. Adv Drug Deliv Rev 2011; 63:822-836.

23. Gaudière $F$, Masson $I$, Morin-Grognet $S$, Thoumire $O$, Vannier JP, Atmani H, Ladam G, Labat B. Mechano-chemical control of cell behaviour by elastomer templates coated with biomimetic Layerby-Layer nanofilms. Soft Matter 2012; 8:8327-8337.

24. Heng BC, Bezerra PP, Meng QR, Chin DWL, Koh LB, Li H, Zhang H, Preiser PR, Boey FY, Venkatraman SS. Adhesion, proliferation, and gene expression profile of human umbilical vein endothelial cells cultured on bilayered polyelectrolyte coatings composed of glycosaminoglycans. Biointerphases 2010; 5:FA53-FA62.

25. Grohmann S, Rothe H, Frant M, Liefeith K. Colloidal force spectroscopy and cell biological investigations on biomimetic polyelectrolyte multilayer coatings composed of chondroitin sulphate and heparin. Biomacromolecules 2011; 12:1987-1997.

26. Tezcaner A, Hicks D, Boulmedais F, Sahel J, Schaaf P, Voegel JC, Lavalle P. Polyelectrolyte multilayer films as substrates for photoreceptor cells. Biomacromolecules 2006; 7:86-94.

27. Hao $Y, X u$ He C, Yang $X$, Huang M, Xing J Chen J. Impact of carbondiimide crosslinker used for magnetic carbon nanotube medi- ated GFP plasmid delivery. Nanotechnology 2011; 22:285103285111.

28. Sung HW, Huang RN, Huang LL, Tsai CC. In vitro evaluation of cytotoxicity of a naturally occurring cross-linking reagent for biological tissue fixation. J Biomater Sci Polym Ed 1999; 10:63-78.

29. Hillberg $A L$, Holmes $C A$, Tabrizian M. Effect of genipin crosslinking on the cellular adhesion properties of layer-by-layer assembled polyelectrolyte films. Biomaterials 2009; 30:4463-4470.

30. Chaubaroux C, Vrana E, Debry C, Schaaf P, Senger B, Voegel JC, Haikel Y, Ringwald C, Hemmerlé J, Lavalle P, Boulmedais F. Collagen-based fibrillar multilayer films crosslinked by a natural agent. Biomacromolecules 2012; 13:2128-2135.

31. Gaudière F, Morin-Grognet S, Bidault L, Lembre $P$, Pauthe $E$, Vannier JP, Atmani H, Ladam G, Labat B. Genipin-crosslinked Layer-by-Layer assemblies: Biocompatible microenvironments to direct bone cell fate. Biomacromolecules 2014; 15:1602-1611.

32. Kim ES, Jeong CS, Moon A. Genipin, a constituent of Gardenia jasminoides Ellis, induces apoptosis and inhibits invasion in MDA-MB-231 breast cancer cells. Oncol Rep 2012; 27:567-72.

33. Ko Hyeonseok, Kim Jee M, Kim Sun-J, Shim So H, Ha Chang $H$, Chang Hyo I., Induction of apoptosis by genipin inhibits cell proliferation in AGS human gastric cancer cells via Egr1/p21 signaling pathway. Bioorg Med Chem Lett 2015; 25:4191-4196.

34. Voinova MV, Rodahl M, Jonson M, Kasemo B. Viscoelastic acoustic response of layered polymer films at fluid-solid interfaces: Continuum mechanics approach. Phys Scr 1999; 59:391-396.

35. Höök F, Kasemo B, Nylander T, Fant C, Sott K, Elwing H. Variations in coupled water, viscoelastic properties, and film thickness of a Mefp-1 protein film during adsorption and cross-linking: A quartz crystal microbalance with dissipation monitoring, ellipsometry, and surface plasmon resonance study. Anal Chem 2001; 73: 5796-5804.

36. Tristán F, Palestino G, Menchaca JL, Pérez E, Atmani H, Cuisinier FJG, Ldam G. Tunable Protein-Resistance of PolycationTerminated Polyelectrolyte Multilayers. Biomacromolecules 2009; 10:2275-2283.

37. Hwang HJ, Larsen J, Krasieva TB, Lyubovitsky JG. Effect of genipin crosslinking on the optical spectral properties and structures of collagen hydrogels. Appl Mater Interfaces 2011; 3:2579-2584.

38. Abdelkebir K, Gaudière F, Morin-Grognet S, Coquerel G, Labat B, Atmani $H$, Ldam G. Evidence of different growth regimes coexisting within biomimetic Layer-by-Layer films. Soft Matter 2011; 7: 9197-9205.

39. Khouja HI, Bevington A, Kemp GJ, Russell RG. Calcium and orthophosphate deposits in vitro do not imply osteoblast mediated mineralization: Mineralization by beta-glycerophosphate in the absence of osteoblasts. Bone 1990; 11:385-391.

40. Volodkin D, Skirtach A, Möhwald H. LbL films as reservoirs for bioactive molecules. Adv Polym Sci 2011; 240:135-161.

41. Huang L, Luo Z, Hu Y, Shen X, Li M, Li L, Zhang Y, Yang W, Liu $P$, Cai K. Enhancement of local bone remodeling in osteoporotic rabbits by biomimic multilayered structures on Ti6Al4V implants. J Biomed Mater Res Part A 2016; 00A:000-000. DOI: 10.1002/ jbm.a.35667.

42. Lee J, Abdeen AA, Tang X, Saif TA, Kilian KA. Geometric guidance of integrin mediated traction stress during stem cell differentiation. Biomaterials 2015; 69:174-183.

43. Abagnale Giulio, Steger Michael, Vu Hoa N, Hersch Nils, Sechi Antonio, Joussen Sylvia, Denecke Bernd, Merkel Rudolf, Hoffmann Bernd, Dreser Alice, Schnakenberg Uwe, Gillner Arnold, Wagner Wolfgang., Surface topography enhances differentiation of mesenchymal stem cells towards osteogenic and adipogenic lineages. Biomaterials 2015; 61:316-326.

44. Lumetti S, Manfredi E, Ferraris S, Spriano S, Passeri G, Ghiacci G, Macalus Galli C. The response of osteoblastic MC3T3-E1 cells to micro- and nanotextured, hydrophilic and bioactive titanium surfaces. J Mater Sci Mater Med 2016; 27:1-9.

45. Syverud K, Pettersen SR, Draget K, Chinga-Carrasco G. Controlling the elastic modulus of cellulose nanofibril hydrogels-scaffolds with potential in tissue engineering. Cellulose 2015; 22:473481.

46. Davies JE. Bone bonding at natural and biomaterial surfaces. Biomaterials 2007; 28:5058-5067. 
47. Zinger O, Zhao G, Schwartz Z, Simpson J, Wieland M, Landolt D, Boyan B. Differential regulation of osteoblasts by substrate microstructural features. Biomaterials 2005; 26:1837-1847.

48. Ban S, Iwaya $Y$, Kono $H$, Sato $H$. Surface modification of titanium by etching in concentrated sulfuric acid. Dent Mater 2006; 22 1115-1120.

49. Trybała A, Szyk-Warszynska L, Warszynski P. The effect of anchoring PEI layer on the build-up of polyelectrolyte multilayer films at homogeneous and heterogeneous surfaces. Colloids Surf A 2009; 343:127-132.

50. Boudou T, Crouzier T, Ren K, Blin G, Picart C. Multiple functionalities of polyelectrolyte multilayer films: New biomedical applications. Adv Mater 2010; 2:441-467.

51. Poursamar SA, Lehner AN, Azami M, Ebrahimi-Barough S, Samadikuchaksaraei A, Antunes APM. The effects of crosslinkers on physical, mechanical, and cytotoxic properties of gelatin sponge prepared via in-situ gas foaming method as a tissue engineering scaffold. Mater Sci Eng C 2016; 63:1-9.

52. Tong $X$, Yang F. Engineering interpenetrating network hydrogels as biomimetic cell niche with independently tunable biochemical and mechanical properties. Biomaterials 2014; 35:1805-1815.

53. Wenzel RN. Resistance of solid surfaces to wetting by water. Ind Eng Chem 1936; 28:988-994.

54. Park JH, Olivares-Navarrete $\mathrm{R}$, Wasilewski CE, Boyan BD, Tannenbaum R, Schwartz Z. Use of polyelectrolyte thin films to modulate osteoblast response to microstructured titanium surfaces. Biomaterials 2012; 33:5267-5277.

55. Gopalakrishnan P, Enqvist E, Wallstrom L, Gattin R Saiter JM. A new green thermoplastic polymer with improved hydrophobic character. Macromol Symp 2010; 290:25-29.

56. Vogler EA. Water and the acute biological response to surfaces. J Biomater Sci Polym Ed 1999; 10:1015-1045..

57. Lipski AM, Pino CJ, Haselton FR, Chen IW, Shastri VP. The effect of silica nanoparticle-modified surfaces on cell morphology, cytoskeletal organization and function. Biomaterials 2008; 29:3836-3846.
58. Richert L, Vetrone F, Yi JH, Zalzal SF, Wuest JD, Rosei F, Nanci A. Surface nanopatterning to control cell growth. Adv Mater 2008; 20:1488-1492.

59. Servaty R, Schiller J, Binder H, Arnold K. Hydration of polymeric components of cartilage-an infrared spectroscopic study on hyaluronic acid and chondroitin sulfate. Int J Biol Macromol 2001; 28: 121-127.

60. Hodde JP, Badylak SF, Brightman AO, Voytik-Harbin SL. Glycosaminoglycan content of small intestinal submucosa. Tissue Eng 1996; 2:209-217.

61. Engler AJ, Sen S, Sweeney HL, Discher DE. Matrix elasticity directs stem cell lineage specification. Cell 2066; 126:677-689.

62. Janson IA, Andrew J, Putnam AJ. Extracellular matrix elasticity and topography: Material-based cues that affect cell function via conserved mechanisms. J Biomed Mater Res Part A 2015; 103A: 1246-1258.

63. Watt FM, Huck WT. Role of the extracellular matrix in regulating stem cell fate. Nat Rev Mole Cell Biol 2013; 14:467-473.

64. Trappmann B, Chen CS. How cells sense extracellular matrix stiffness: A material's perspective. Curr Opin Biotechnol 2013; 24: 948-953.

65. Kuboki Y, Kudo A, Mizuno M, Kawamura M. Time-dependent changes of collagen cross-links and their precursors in the culture of osteogenic cells. Calcif Tissue Int 1992; 50:473-480.

66. Zhao L, Mei S, Chu PK, Zhang Y, Wu Z. The influence of hierarchical hybrid micro/nano-textured titanium surface with titania nanotubes on osteoblast functions. Biomaterials 2010; 31:5072-5082.

67. Pedraza CE, Chien YC, McKee MD. Calcium oxalate crystals in fetal bovine serum: Implications for cell culture, phagocytosis and biomineralization studies in vitro. J Cell Biochem 2008; 103: 1379-1393.

68. Hashimoto A, Chiu L, Sawada K, Ikeuchi T, Fujita L, Takedachi M, Yamaguchi Y, Kawata S, Murakami S, Tamiya E. In situ Raman imaging of osteoblastic mineralization. J Raman Spectrosc 2014; 45:157-161. 